\title{
DETERMINING OPTIMAL ELECTRICITY TECHNOLOGY MIX WITH HIGH LEVEL OF WIND POWER PENETRATION
}

\author{
Cedric De Jonghe (corresponding author) ${ }^{\mathrm{a}}$, Erik Delarue ${ }^{\mathrm{b}}$, Ronnie Belmans ${ }^{\mathrm{a}}$, William D’haeseleer ${ }^{\mathrm{b}}$ \\ Cedric.DeJonghe@esat.kuleuven.be, Tel. +32 163211 47, Fax +32 16321985 \\ ${ }^{a}$ University of Leuven (K.U.Leuven) Energy Institute, ELECTA branch (Electric Energy and \\ Computer Architectures), Kasteelpark Arenberg 10 box 2445 / B-3001 Leuven / Belgium. \\ ${ }^{b}$ University of Leuven (K.U.Leuven) Energy Institute, TME branch (Applied Mechanics and Energy
}

Conversion), Celestijnenlaan 300A box 2421 / B-3001 Leuven / Belgium.

\begin{abstract}
Notwithstanding its variability and limited controllability, wind power is expected to contribute strongly to electricity generation from renewable energy sources in the coming decades. Treating wind power as nondispatchable by subtracting its output from the original load profile, results in a net load profile, which must be covered by conventional power generation. The screening curve methodology is a first approximation to find the optimal generation technology mix, based on relative cost levels. However, increased variability of the net load profile, due to wind power generation, strongly influences system operation. Therefore a static linear programming investment model is developed to determine the optimal technology mix. This alternative methodology shows a reduced capacity of inflexible generation after including operational constraints to properly account for net load variability. In order to illustrate this methodology, an example is set up, showing the sensitivity with respect to ramp rates of conventional generation, transmission interconnection and energy storage. The comparison of those different sources of system flexibility suggests that energy storage facilities better facilitate the integration of wind power generation.
\end{abstract}

Keywords - Technology mix - wind power - screening curve- variability - wind power curtailment

1 Introduction

European energy policy focuses on security of supply, improved sustainability and the competitiveness of the energy sector. The installation of renewables contributes directly or indirectly to these aspects, even though benefits with respect to sustainability are mostly emphasized. As the European Commission aspires to deploy a large share of Electricity from Renewable Energy Sources (RES-E), interest must be paid to the impact of these technologies on the operation and development of the electricity system [1], on the transmission grid [2], ancillary services [3] and the generation technology mix. Finally, the cost faced by end consumers has to be monitored carefully [4]. Targets for shares of renewables in the final energy demand are set by the European Commission. Although Member States can choose between different technologies, significant market experience has been developed with respect to wind power, especially onshore. This technology is expected to contribute strongly to reaching these targets.

Whereas wind power is a nearly zero marginal cost technology, it is a variable energy source which is only controllable to a limited extent [5]. This characteristic has an impact on different elements of the power system. The distribution grid might get overloaded due to locally connected wind turbines. Next, the transmission grid, being the backbone of the power system, needs to deal with major imbalances between regions. Finally, additional flexibility offered by operational backup [6] and balancing power [7] is needed to handle fluctuations in power supply.

The present paper analyzes the impact of a high level of wind power penetration on the optimal future power technology mix. It is organized as follows. In the following section, a first approach is presented based on the screening curve methodology. In section 3, a Linear Programming (LP) investment planning model is developed as an alternative methodology, accounting for the variable character of load profiles. In section 4, an illustrative example focuses on the impact of including operational constraints on the optimal generation technology mix. A sensitivity analysis compares 
different sources of generation flexibility, i.e. ramp rates of conventional generation units, transmission interconnection and energy storage. Finally, conclusions are drawn in section 5.

2 Optimal technology mix based on screening curve methodology

\subsection{Theoretical approach}

Demand for electricity can be described by means of a load duration curve. This curve is built by sorting load levels starting from the highest level in a certain region at hourly intervals, typically for one year, i.e., 8760 hours (Figure 1). Given this representation, the number of hours where demand is below or above a certain level can easily be read [8], [9].

The screening curve methodology uses load duration curves to determine an optimal mix of generation technologies $i$ able to meet load in a cost effective way or in a perfect competition market context [10]. The relative shares of different technologies $i$ in the optimal mix are based on fixed and variable costs. The annualized fixed costs $\left(F_{i}\right)$ are expressed in terms of [k€/MW]. These fixed costs consist of the investment cost $\left(I N V_{i}\right)$ and the fixed O\&M cost $\left(F O M_{i}\right)$. The variable costs $V_{i}$ consist of fuel $\left(F U_{i}\right)$ and variable $\mathrm{O} \& \mathrm{M}$ cost $\left(V O M_{i},\right)$ both expressed in terms of [€/MWh]:

$$
\begin{aligned}
& \forall \mathrm{i} \in \mathrm{I}: \mathrm{F}_{\mathrm{i}}=\mathrm{INV}_{\mathrm{i}}+\mathrm{FOM}_{\mathrm{i}} \\
& \forall \mathrm{i} \in \mathrm{I}: \mathrm{V}_{\mathrm{i}}=\mathrm{FU}_{\mathrm{i}}+\mathrm{VOM}_{\mathrm{i}}
\end{aligned}
$$

These relative cost levels determine the optimal number of operating hours. A relative change in these cost levels therefore results in a redistribution of the optimal mix ${ }^{1}$. In this paper, four technologies are included, i.e. base, mid, peak and high peak, with different cost categories (Table I) ${ }^{2}$. These costs are based on data from the International Energy Agency [11].

Table I: Cost categories for different conventional technologies

\begin{tabular}{llcccc}
\hline Cost category & & Base & Mid & Peak & High Peak \\
\hline Investment & {$[\mathrm{k} € / \mathrm{MW}]$} & 155 & 65 & 25 & 15 \\
Fixed O\&M & {$[\mathrm{k} € / \mathrm{MW}]$} & 65 & 35 & 15 & 10 \\
Fuel & {$[€ / \mathrm{MWh}]$} & 10 & 20 & 35 & 65 \\
Variable O\&M & {$[€ / \mathrm{MWh}]$} & 5 & 10 & 10 & 10 \\
\hline
\end{tabular}

In order to determine the optimal mix, the technology costs [€/MW] have to be calculated given the number of operating hours (Figure 1). A cost minimization makes sure that base load plants face the highest number of operating hours. This way, these technologies have a higher yearly energy output per installed capacity in contrast to peak load plants. The lowest load levels which have not been exceeded more than $\mathrm{M}$ hours are fully covered by base load capacity $\mathrm{MW}_{\mathrm{B}}$. $\mathrm{M}$ is referred to as a technology switching point. For higher load levels which are reached between $\mathrm{P}$ and $\mathrm{M}$ hours per year, mid load generation units are the market clearing technology. It is efficient to build this technology type to meet demand levels that will only last for a shorter period of the year. An optimal mid load capacity of $\mathrm{MW}_{\mathrm{M}}$ is installed. Correspondingly, the optimal peak $\left(\mathrm{MW}_{\mathrm{P}}\right)$ and high peak $\left(\mathrm{MW}_{\mathrm{hP}}\right)$ generation technology capacity levels are determined. Sometimes Value Of Lost Load (VOLL) is added as a last option to balance generation and demand in case of generation shortage. Consequently, system balance is attained at the demand-side of the system. No fixed costs are involved with this option. The corresponding variable costs are highly uncertain and can be determined by the loss of social welfare.

\footnotetext{
${ }^{1}$ The presence of the European Union Emission Trading Scheme (EU ETS) is relevant in this matter. The introduction of a cost for CO emissions influences the variable costs of technologies. The effect of a $\mathrm{CO}_{2}$ tax or an emission allowance price is not investigated, but certainly reduces the share of strongly polluting technologies. This cost could be easily added to the given fuel costs.

2 The fuel cost for each technology is taken as a constant. Therefore, an average efficiency of the generating power plants for each technology is assumed. As the modeling approach developed in this paper considers technologies in general, rather than separate power plants, it does not allow taking into account the actual heat-rate curve, i.e., the load dependent efficiency of a power plant.
} 
The screening curve methodology can be used as a first approximation. The relative cost levels in combination with the load duration curve define the optimal mix of base, mid, peak and high peak plants. A changing load duration curve results in a different optimal mix. Changes in the load duration curve can, amongst other, be caused by energy efficiency improvements, demand-side effects or largescale wind power deployment. As wind power is generated at zero marginal costs and is considered non-dispatchable, it is subtracted from the original hourly load level, resulting in a so-called net load level. Consequently, wind power generation can be seen as negative load causing a load duration change [12]. If wind power output would be greater than electricity demand for one hour, wind power curtailment, also referred to as wasted wind [13], would be applied to eliminate negative net load levels.

Three load duration curves of net demand levels are shown in Figure 2. These curves are illustrative representations of different scenarios assuming increasing demand levels and simultaneously increasing levels of wind power penetration ${ }^{3}$. The full line corresponds to a scenario with a $20 \%$ share of wind energy in the electricity generation portfolio. Increasing demand levels combined with a further penetration of wind energy corresponds to the dashed and dotted line for a 30\% and 35\% wind energy share respectively. At the left hand side of hour 6000, illustrative load duration curves are situated above the full line (reference curve). The more pronounced upward tail can be explained by "high demand - low wind" situations on the left hand side of the graph. Low net load situations on the right hand side of the graph correspond to "low demand - high wind" situations.

The optimal mix using the screening curve methodology is given in Figure 3 without taking into account previously installed capacities. With the assumed high wind power penetration levels, the shares of the different generation technologies are roughly equally distributed. These shares will be compared with the optimal generation technology mix after inclusion of operational constraints in section 4 .

3 Optimal technology mix accounting for variability

The increased variability, as a result of increased wind power deployment, has an impact on conventional generation [14]. Long-term investment or generation expansion planning models [15] present little information on the inclusion of operational aspects and optimize for a limited number of demand levels. Some aspects have been added to integrated resource planning models, but the chronologic sequence of hourly load levels and power plant dynamics are typically neglected [16], [17]. Unit commitment models [18], [19], integrate highly detailed technical characteristics, while hindering appropriate investment decision making, as only a limited time frame is considered. Therefore a methodology has to be developed allowing the incorporation of variability at the demandside, with volatile net demand profiles, and the operational constraints at the supply-side into longterm investment planning.

\subsection{Basic model description}

A cost minimizing LP model has been developed. It is a static optimization model defining the optimal generation technology mix. The standard formulation of an investment model is used [15], distinguishing between installed capacity with fixed costs (Eq.(1)) and electricity generation with variable costs (Eq.(2)). The optimal mix of generation technologies is determined by minimizing the annual system cost as given in Eq. (3). This optimization defines the optimal, installed capacity ( cap $_{i}$ ) and hourly electric energy generation $\left(g_{i, j}\right)$.

$$
\text { Minimize Cost }=\sum_{\mathrm{i}} \mathrm{F}_{\mathrm{i}} * \operatorname{cap}_{\mathrm{i}}+\sum_{\mathrm{i}, \mathrm{j}} \mathrm{V}_{\mathrm{i}} * \mathrm{~g}_{\mathrm{i}, \mathrm{j}}
$$

The hourly electric energy generation is equivalent to the instantaneous power (although averaged over a time step of one hour), expressed in [MWh/h]. For each technology type $i$, the hourly generated amount of energy is restricted by the installed capacity, given that the total amount of energy

\footnotetext{
${ }^{3}$ A detailed data description is given in section 4.1 .
} 
generated meets hourly demand:

$$
\begin{aligned}
& \forall \mathrm{i} \in \mathrm{I}, \forall \mathrm{j} \in \mathrm{J}: \mathrm{g}_{\mathrm{i}, \mathrm{j}} \leq \operatorname{cap}_{\mathrm{i}} \\
& \forall \mathrm{j} \in \mathrm{J}: \sum_{\mathrm{i}} \mathrm{g}_{\mathrm{i}, \mathrm{j}}=\operatorname{DEMAND}_{\mathrm{j}}
\end{aligned}
$$

In order to incorporate variability into the model, wind power is treated as negative demand (as mentioned before). As a consequence, variability is shifted from the supply-side to the demand side. This way of incorporating wind power only accounts for the variability of wind. Using wind power injections as negative demand does not account for the unpredictability of wind power or the load profile.

Hourly wind energy generation is the result of a wind-generated electric power profile $\left(W P_{j}\right)[\%]$ multiplied by the level of installed capacity (WCAP), expressed in [MW] (Eq. (6)). The resulting hourly NET_DEMAND, has to be covered by conventional units. Correspondingly, Eq. (5) has to be replaced by Eq. (7).

$$
\begin{aligned}
& \forall \mathrm{j} \in \mathrm{J}: \text { NET_DEMAND }_{\mathrm{j}}=\text { DEMAND }_{\mathrm{j}}-\left(\mathrm{WP}_{\mathrm{j}} * \mathrm{WCAP}\right) \\
& \forall \mathrm{j} \in \mathrm{J}: \sum_{\mathrm{i}} \mathrm{g}_{\mathrm{i}, \mathrm{j}}=\text { NET_DEMAND }_{\mathrm{j}}
\end{aligned}
$$

This formulation yields the same solution as the screening curve methodology (see section 2), since so far no operational constraints are considered.

\subsection{Inclusion of operational constraints}

The basic LP model as described above calculates the optimal shares of different technology types without taking into account any technical aspects. Operational constraints such as a periodic maintenance [16], must run levels and ramp rates can be added to the model ${ }^{4}$. A required reserve margin is not included in this paper as uncertainty about demand levels is dealt with by the balancing requirement constraint. This requirement is also included in order to account for the unpredictability of both hourly wind power injections and demand-side variability. The capacity restriction on energy generation in Eq.(4) has to be replaced by Eq.(8) in order to integrate the need for periodic maintenance. A technology specific periodic maintenance parameter $\left(P M_{i}\right)$ is introduced to downscale the available capacity.

$$
\forall \mathrm{i} \in \mathrm{I}, \mathrm{j} \in \mathrm{J}: \mathrm{g}_{\mathrm{i}, \mathrm{j}} \leq \mathrm{cap}_{\mathrm{i}} * \mathrm{PM}_{\mathrm{i}}
$$

Less flexible generation technologies will not be operated below certain output levels. Therefore a technology specific must run $\left(M R_{i}\right)$ level, also referred to as a partial load constraint can be integrated as in Eq. (9). An alternative formulation of this partial load constraint is suggested in [20].

$$
\forall \mathrm{i} \in \mathrm{I}, \mathrm{j} \in \mathrm{J}: \mathrm{g}_{\mathrm{i}, \mathrm{j}} \geq \mathrm{MR}_{\mathrm{i}} * \mathrm{cap}_{\mathrm{i}}
$$

The constraints above (Eq. (8)-(9)) determined by the parameters $P M_{i}$ and $M R_{i}$ have no inter-period characteristic. Information about the chronologic sequence of hourly load levels is still not included into the model. Conversely, the inclusion of ramp rates of conventional generation units and a balancing requirement have a more complicated impact on the optimal mix as the sequence of hourly load and wind power input levels are included. This aspect is important, given the fluctuating wind power output.

Both ramp rates and a balancing requirement depend on the output flexibility of generation technologies. Operating a base load plant efficiently requires a higher yearly energy output per installed capacity. A deviation from the optimal point of operation harms the efficiency and the related low variable costs. Additionally, strongly adjusting the energy output of base load plants significantly

\footnotetext{
${ }^{4}$ Other operational aspects such as start-up cost, minimum operating levels and minimum up-/down times would introduce binary variables. This would make it a Mixed Integer Linear Program (MILP). Solving a MILP investment model to define the optimal generation mix poses computational difficulties for a one year dataset. Therefore, operational aspects requiring binary variables are not considered in this model.
} 
reduces the lifetime of these units. Consequently a lower flexibility, translated to a more stringent ramp rate, is ascribed to a base load technology. This is also true for a mid and peak load generation unit, but to a lesser degree. Therefore, a less stringent ramp rate is allowed for these generation units.

Ramp rates typically express flexibility as a percentage of the total installed capacity of a specific generation technology. In order to reduce the generation output flexibility when a plant is operated at lower output levels (see section 4.1), distinction is made between committed and non-committed capacity. A lower flexibility in terms of percentage is attributed to non-committed than committed capacity. This is respectively indicated by the parameters $R A M P \_N C$ and $R A M P \_C$. Only for high peak load capacity $100 \%$ flexibility is assumed for upward as well as downward ramping.

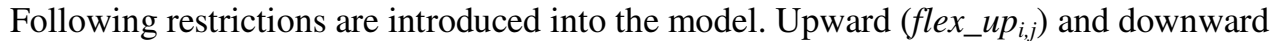
(flex_down, ) flexibility of each generation technology are calculated in Eq.(10) and Eq.(12) for each hour. The former is restricted by the total amount of non-committed capacity Eq. ((11)), meaning that the generation output can never ramp up more in one hour than the non-committed capacity in the previous hour. Correspondingly, the latter is restricted by the output level or committed capacity in the previous hour (Eq.(13)). This constraint is redundant after including Eq. (15), assuming non-negative output levels $g_{i, j}$, but is required when negative balancing requirement Eq. (19) is introduced.

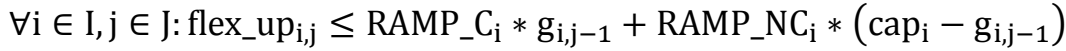

$$
\begin{aligned}
& \forall \mathrm{i} \in \mathrm{I}, \mathrm{j} \in \mathrm{J}: \text { flex_up }_{\mathrm{i}, \mathrm{j}} \leq \mathrm{cap}_{\mathrm{i}}-\mathrm{g}_{\mathrm{i}, \mathrm{j}-1} \\
& \forall \mathrm{i} \in \mathrm{I}, \mathrm{j} \in \mathrm{J}: \text { flex_down }_{\mathrm{i}, \mathrm{j}} \leq \mathrm{RAMP}_{-} \mathrm{C}_{\mathrm{i}} * \mathrm{~g}_{\mathrm{i}, \mathrm{j}-1}+\mathrm{RAMP}_{-} \mathrm{NC}_{\mathrm{i}} *\left(\mathrm{cap}_{\mathrm{i}}-\mathrm{g}_{\mathrm{i}, \mathrm{j}-1}\right) \\
& \forall \mathrm{i} \in \mathrm{I}, \mathrm{j} \in \mathrm{J}: \text { flex_down }_{\mathrm{i}, \mathrm{j}} \leq \mathrm{g}_{\mathrm{i}, \mathrm{j}-1}
\end{aligned}
$$

For every hour, a constraint is introduced into the model to restrict the generation fluctuations of each technology type separately by Eq. (14) and (15).

$$
\begin{aligned}
& \forall i \in I, \forall j \in J /\{1\}: g_{i, j} \leq g_{i, j-1}+\text { flex_up }_{i, j} \\
& \forall i \in I, \forall j \in J /\{1\}: g_{i, j} \geq g_{i, j-1}-\text { flex_down }_{i, j}
\end{aligned}
$$

A balancing requirement is also included as operational constraint. This constraint is important for a system with large-scale integration of wind power. Additional wind power injections require additional balancing power for both positive and negative regulation. Average and maximum balancing power requirements are suggested in [21] for positive as well as negative regulation. For positive regulation, a balancing power requirement $\left(P O S \_B A L A N C E_{j}\right)$ equal to $9 \%$ of the wind power capacity should be kept available on average. During high wind situations, the positive balancing power requirement increases up to $19 \%$ of wind power capacity. For negative regulation, a balancing power requirement $\left(N E G_{-} B A L A N C E_{j}\right)$ of $8 \%$ of the wind power capacity should be kept available on average. During high wind situations, the negative balancing power requirement increases up to $15 \%$ of wind power capacity. Wind power capacity is assumed to be equal to the maximum wind power injections (PEAK_WIND) of the time series and the levels of balancing power are assumed to increase linearly with increasing wind power injection (Table III).

$$
\begin{aligned}
& \forall \mathrm{j} \in \mathrm{J}: \text { POS_BALANCE } \mathrm{j}=\text { A_POS } * \text { WIND }_{\mathrm{j}}+\mathrm{B}_{-} \mathrm{POS} * \text { PEAK_WIND } \\
& \forall \mathrm{j} \in \mathrm{J}: \mathrm{NEG}_{-} \text {BALANCE } \mathrm{j}_{\mathrm{j}}=\mathrm{A} \_\mathrm{NEG} * \mathrm{WIND}_{\mathrm{j}}+\mathrm{B} \_\mathrm{NEG} * \text { PEAK_WIND }
\end{aligned}
$$

The balancing power requirements have to be fulfilled by the aggregated upward or downward flexibility of conventional generation units.

$$
\begin{aligned}
& \forall \mathrm{j} \in \mathrm{J}: \text { POS_BALANCE }_{\mathrm{j}} \leq \sum_{\mathrm{i}} \text { flex_up }_{\mathrm{i}, \mathrm{j}} \\
& \forall \mathrm{j} \in \mathrm{J}: \text { NEG_BALANCE }_{\mathrm{j}} \geq \sum_{\mathrm{i}} \text { flex_down }_{\mathrm{i}, \mathrm{j}}
\end{aligned}
$$

\subsection{Sources of flexibility}

The inclusion of these operational constraints restricts the flexibility of conventional generation 
units. At the same time increased net demand variability results in a need for additional system flexibility. Three options are added to the model to improve system flexibility: wind power curtailment, cross-border transmission interconnections and energy storage. Enhancing power plant flexibility (by increasing the ramp rates of conventional technologies) also adds to system flexibility and is therefore also included in the sensitivity analysis below. Demand response is another clear source of flexibility [22], but is subject for further research.

\subsubsection{Wind power curtailment}

Wind power curtailment can be used to reduce the amount of wind power fed into the grid during high wind situations. This amount of discarded energy will become substantial for increasing wind power generation [23]. This intervention softens hourly wind variability and is therefore considered to indirectly improve system flexibility. To introduce wind power curtailment into the model, Eq. (6) is replaced by Eq.(20). The positive variable curtailment $_{j}$ is added to the model. The amount of curtailment is restricted by the amount of wind power produced by adding following constraint:

$$
\begin{aligned}
& \forall \mathrm{j} \in \mathrm{J}: \sum_{\mathrm{i}} g_{\mathrm{i}, \mathrm{j}}=\text { NET_DEMAND }_{\mathrm{j}}+\text { curtailment }_{\mathrm{j}} \\
& \forall \mathrm{j} \in \mathrm{J}: \text { curtailment }_{\mathrm{j}} \leq \mathrm{WIND}_{\mathrm{j}}
\end{aligned}
$$

Wind power curtailment is economically optimal when it prevents investing in additional flexible generation capacity or when it allows increasing power generation from a technology with low variable costs but limited flexibility. Depending on the market context behind, wind power curtailment has to be dealt with in a different way. Assume a cost minimizing generator in a perfect competition market setting, with wind power generation in its portfolio. This market party faces an opportunity costs when his wind power output is reduced. Due to curtailment of this green energy source, the generator misses out on the cohering subsidy. Consequently, this opportunity cost (CURTAIL_COST) should be based on the feed-in tariff or the green certificate price in the region of curtailment ${ }^{5}$. Alternatively, assuming a central planner market setting, total costs for the society are minimized. In this context, it does not make a difference whether the central planner or the end user faces the cost of generating renewable energy. In this paper, we assume a perfect competition market setting with a cost minimizing generator. Supposing hourly time intervals and applying wind power curtailment for at least one hour, the cost of curtailing power is expressed in [€/MWh]. Consequently the objective function has to be changed to:

$$
\text { Minimize Cost }=\sum_{i} F_{i} * \text { cap }_{i}+\sum_{i, j} V_{i} * g_{i, j}+\sum_{j}{\text { CURTAIL_COST } * \text { curtailment }_{j}}
$$

\subsubsection{Transmission interconnection}

In general, power systems are connected to neighboring control areas. Those transmission interconnections create cross-border equilibration opportunities which improve system flexibility. Importing or exporting power during critical system situations impacts the operation and optimal mix of generation capacity in the exporting as well as in the importing region. Note that this means of flexibility heavily relies on neighboring systems as demand and wind power injections in neighboring regions are highly correlated. A positive variable (export $t_{j}$ ) is added to Eq. (6) allowing the export of excess power during high wind situations. The amount of power exported is restricted by the available transmission capacity.

$$
\begin{aligned}
& \forall \mathrm{j} \in \mathrm{J}: \sum_{\mathrm{i}} \mathrm{g}_{\mathrm{i}, \mathrm{j}}=\text { NET_DEMAND }_{\mathrm{j}}+\text { export }_{\mathrm{j}} \\
& \forall \mathrm{j} \in \mathrm{J}: \text { export }_{\mathrm{j}} \leq \text { TRANSMISSION_CAP }^{-}
\end{aligned}
$$

In the reference scenario of this model, only export of excess power is permitted. Importing power during moments of high demand could easily be integrated by adding a positive variable (import t $_{j}$ ) to Eq. (23), restricted by the transmission capacity. This variable would also have to be included into the objective function linked with a certain cost of import. This corresponds to the creation of a new

\footnotetext{
${ }^{5}$ Negative prices can already be seen in high wind regions. On the German spot market (European Energy Exchange: EEX), negative prices up to $-119 € / \mathrm{MWh}$ occur on the day-ahead market. Similar negative price occur on the Danish real time market.
} 
generation technology at a limited (only variable) cost with a restricted total capacity. In the sensitivity analysis, different transmission interconnection capacities are assumed allowing both import and export of power.

\subsubsection{Energy storage}

Energy storage is another source of system flexibility. Opportunities for different energy storage technologies can be analyzed [22], whereas this model focuses on pumped hydro. A pumped hydro facility can charge ( pump_up $_{j}$ ) and discharge (turbine ) $_{j}$ energy given the capacity $[\mathrm{MW}]$ of the turbine. The dispatch of the pump unit will balance generation and net demand bearing in mind the efficiency $(E F F)$. The positive amount of energy stored $\left(\right.$ stored $\left._{j}\right)$ depends on the previous hour $(j-1)$ and on the pump dispatch of last hour (j) (Eq. (26)). It is restricted by the total storage capacity (Eq. (27)).

$$
\begin{aligned}
& \forall \mathrm{j} \in \mathrm{J}: \sum_{\mathrm{i}} g_{\mathrm{i}, \mathrm{j}}=\text { NET_DEMAND }_{\mathrm{j}}+\text { pump_up }_{\mathrm{j}}-\text { tubine }_{\mathrm{j}} * \mathrm{EFF}_{\mathrm{DF}} \\
& \forall \mathrm{j} \in \mathrm{J}: \text { stored }_{\mathrm{j}}=\text { stored }_{\mathrm{j}-1}+\text { pump_up }_{\mathrm{j}} * \text { EFF }- \text { turbine }_{\mathrm{j}} \\
& \forall \mathrm{j} \in \mathrm{J}: \text { stored }_{\mathrm{j}} \leq \text { STORAGE_CAP }^{-}
\end{aligned}
$$

Illustrating example

\subsection{Data and assumptions}

The described model is now applied to an illustrative example assuming high wind power penetration. In order to integrate demand and wind power time series with a realistic variability, historical data are used ${ }^{6}$. These time series are corrected reflecting high wind power penetration with a wind energy share between 30\% and 35\% (cfr Figure 2). A cost minimization is done on a hourly interval for a period of one year (8760 steps).

For this illustrative example, a cost of $100 € / \mathrm{MWh}$ for wind power curtailment is included, inspired by negative prices observed in the German and Danish energy market. A $250 \mathrm{MW}$ pump/turbine capacity is assumed as well as a $250 \mathrm{MW}$ transmission interconnection. This interconnection is only used to export energy at the price of $0 € / \mathrm{MWh}$. This is realistic given the merit order effect of large amounts of wind power [24]. Different ramp rates, levels of transmission interconnection and pump/turbine capacities are used to illustrate the impact of these parameters on the model results. In this sensitivity analysis, import of power is allowed at a cost of $100 € / \mathrm{MWh}$.

For each optimization it is assumed that total energy storage capacity corresponds to 5 hours pumping up water at nominal capacity. $90 \%$ efficiency is considered whenever the storage unit is used to pump up or as a turbine ${ }^{7}$. Periodic maintenance $(P M)$ is set to $90 \%$ and a must run requirement of $10 \%$ of the installed capacity is included for base and mid load generation technologies.

Ramp rates are introduced as a percentage of the total installed capacity of a technology (Table II). Ramp rates are included in a unit commitment problem in [25], allowing to ramp up or down coal fired generation unit in four hours. Reducing the ramping time is allowed by considering a ramping penalty as the cost of shortening the service life of the turbine rotor. Full ramp up and down times of 3 hours are used in [26] for coal and nuclear facilities and 2 hours for gas and petroleum fired combined cycle generators. Additionally, distinction can be made between plant equipment vendors, who are typically more optimistic about ramp rates, and actual plant operators. These plant operators report ramp rates being 2.5 up to 5 times lower than those suggested by the plant vendors in [27]. Furthermore, ramp rates depend on plant loading and would only have $60 \%$ of the full ramping capacity when a plant is operated at lower output levels. Note that the model works on an aggregated technology level, rather than on a power plant basis. Hence, the introduced ramp rates should not be directly compared to ramp rates of individual power plants, which might be higher, but should be considered as possible generation technology variations. This reasoning is supported by the impact of start-up situations. Start-up costs, minimum run and minimum on/off times might make plant operators averse from starting up all individual units. Consequently, the aggregated generation output

\footnotetext{
${ }^{6}$ Historical data are easily accessible on the website of the Danish grid owner Energinet (http://www.energinet.dk/).

${ }^{7}$ The efficiency of the total cycle of energy storage is $81 \%$.
} 
flexibility could be considered to be lower than individual ramp rates. The ramp rates used, should be considered as methodological, but are inspired by a literature review ([25] [26] [27]) and expert discussions.

Table II: Technology specific ramp rates

\begin{tabular}{lcc}
\hline Technology & $\begin{array}{c}\text { Ramp rate committed capacity } \\
{\left[\% / \text { hour] }\left(R A M P \_C_{i}\right)\right.}\end{array}$ & $\begin{array}{c}\text { Ramp rate non-committed } \\
\text { capacity [\%/hour] }\left(R A M P \_N C_{i}\right)\end{array}$ \\
\hline High peak load & 100 & 100 \\
Peak load & 80 & $80 * 60 \%$ \\
Mid load & 50 & $50 * 60 \%$ \\
Base load & 33.3 & $33.3 * 60 \%$ \\
\hline
\end{tabular}

Based on the coherence between costs (Table I) and ramp rates, base and mid load technologies could be seen as nuclear and coal units respectively, whereas peak and high peak load technologies could correspond to a CCGT and a more flexible oil or gas fired turbine. Balancing power requirement data, accounting for the uncertainty in the wind and demand profile, is summarized in Table III.

Table III: Balancing power requirements

\begin{tabular}{ccc}
\hline & Average [\%] & Maximum [\%] \\
\hline Positive regulation & 9 & 8 \\
Negative regulation & 19 & 15 \\
\hline Linearization & $A[\%]$ & $B[\%]$ \\
\hline Positive regulation $\left(\_P O S\right)$ & 12.5 & 6.5 \\
Negative regulation $\left(\_N E G\right)$ & 8.75 & 6.25 \\
\hline
\end{tabular}

\subsection{Simulation results}

Inclusion of operational constraints into the model allows us to properly consider hourly net load variability given high wind power penetration. A reference case is set up to see the impact of those operational constraints on the optimal mix, compared with the screening curve methodology. Additionally, a sensitivity analysis illustrates the impact of relevant parameters on the optimal installed capacities.

\subsubsection{Reference case}

The screening curve methodology is compared with a reference case, taking into account the variable demand profile and technical operating constraints (Figure 3). Due to the increased variability, less flexible generation technologies are replaced by others offering a higher degree of modulation. Comparing the optimal mix based on the screening curve methodology with this reference case makes clear the significant impact of including operational constraints. Base load capacity is mainly replaced by mid load capacity. But the share of peak load increases as well.

The electricity generation output by different technologies for a weekly load profile is presented in Figure 4. This corresponds to the optimal dispatch for one week given an optimal mix based on the optimization for one year. This result does not correspond to a unit commitment solution. Technology categories are considered instead of separated units with start-up costs, minimum up- and down-time, etc. The thick full line indicates net demand levels. When zero net demand levels occur (e.g. from hour 124 until 130), power generation levels are still above zero as a result of operational constraints such minimum run levels. The impact of ramp rates on the generation output fluctuation can clearly be observed in the case of base load around hour 10 and 90. Excess energy during those hours can be stored, exported or curtailed if originating from wind power. Further, the lower base load generation output, similar to a lower optimal base load capacity is apparent when including operational constraints. 


\subsubsection{Ramp rates}

The optimal mix with different ramp rates for base and mid load generation technologies are shown in Figure 5 and Figure 6 respectively. The optimal mix is clearly more sensitive for ramp rates on the base load than mid load technologies. As suggested in section 3.2, different ramp rates are suggested by plant vendors and operators. Therefore, both a more stringent and a more flexible ramp rate are used for base load in the sensitivity analyses below. The more flexible rate corresponds to the data in Table II, while in the more stringent case, the base load ramp rate is divided by two. The ramp rate of the mid load technology only has an impact when assuming very low flexibility. In that case, this technology is replaced in the optimal technology mix by base and peak load technologies.

\subsubsection{Transmission interconnection flexibility}

Moving from an isolated power system to a well interconnected situation increases the flexibility by spreading out fluctuations over several regions. This analysis assumes that the neighboring region is always capable of absorbing energy at a cost of $0 € / \mathrm{MWh}$ and capable of exporting energy at a cost of $100 € / M W h$. Figure 7 and Figure 8 show that an increasing interconnection capacity reduces the total installed capacity in a region as a result of a lower high peak capacity. Allowing export of excess power does not have a significant impact on the optimal amount of base load capacity. If a reserve margin would be included, the reduction of the optimal total installed capacity would not occur.

\subsubsection{Energy storage flexibility}

Energy storage is another source of flexibility for power system operation. Using transmission interconnections for increasing system flexibility permits export of excess power during low price moments (system is long) and import of power during high price moments (system is short). A storage facility offers the opportunity to store energy at a low price and to use it during high price moments. By using the storage unit, the optimal amount of high peak capacity can be reduced. Additionally, by storing excessive power generation, the optimal capacity of base load is increased.

\section{Conclusions}

This paper analyzes the impact of inclusion of operation constraints in long term generation investment planning. The traditional screening curve methodology is compared with an extended linear programming model including operational constraints. A sensitivity analysis is performed to investigate the impact of these constraints on the optimal generation technology mix.

The screening curve methodology is applicable as a first approximation to determine the optimal generation technology mix in the long run. Based on relative cost levels, the optimal number of operating hours is calculated. The optimal number of operating hours combined with the shape of the load duration curve finally determines the shares of different technologies.

As wind power deployment will increase significantly in the coming years, power generation flexibility must increase as well. Operational constraints focusing on periodic maintenance, must run requirements, generation fluctuations and balancing requirements are added to the static LP model, which is then suggested as the alternative methodology to define the optimal mix. Comparing this model with the screening curve methodology demonstrates the impact of adding operational elements in long run investment planning.

It is argued that the capacity of peak load technologies and even high peak load technologies need not be increased significantly. Base load capacity, on the other hand, is replaced by more flexible mid load generation capacity given large-scale wind power penetration. Transmission interconnection and energy storage are added to the model as different sources of system flexibility. Assumed ramp rates of base load generation are the dominant parameter when defining the optimal mix, whereas the mid load generation ramp rates only have a limited impact. Since the base load ramp rates are crucial for the model result, both a more flexible and a more stringent rate are applied in the sensitivity analysis on transmission interconnection and energy storage capacity. Both sources of flexibility facilitate a decrease in the optimal total installed capacity. However, only an energy storage unit is able to offer the required flexibility to increase the amount of base load capacity in the optimal generation technology mix. 
The authors are grateful for suggestions by and discussions with Daniel Kirschen (The University of Manchester) and Yann Rebours (EDF). The authors would further like to thank the anonymous reviewers for their comments and suggestions.

$7 \quad$ References

[1] G. Strbac, a Shakoor, M. Black, D. Pudjianto, and T. Bopp, "Impact of wind generation on the operation and development of the UK electricity systems," Electric Power Systems Research, vol. 77, Jul. 2007, pp. 1214-1227.

[2] P. Ostergaard, "Transmission-grid requirements with scattered and fluctuating renewable electricity-sources," Applied Energy, vol. 76, Nov. 2003, pp. 247-255.

[3] P. Ostergaard, "Ancillary services and the integration of substantial quantities of wind power," Applied Energy, vol. 83, May. 2006, pp. 451-463.

[4] L. Dale, “Total cost estimates for large-scale wind scenarios in UK,” Energy Policy, vol. 32, Nov. 2004, pp. 19491956.

[5] K. De Vos, P.S. Perez, and J. Driesen, "The Participation in Ancillary Services by High Capacity Wind Power Plants: Reserve Power," Conference on the promotion of Distributed Renewable Energy Sources in the Mediterranean region (DISTRES), Nicosia, Cyprus: 2009.

[6] P. Luickx, "The Backup of Wind Power: Analysis of the Parameters Influencing the Wind Power Integration in Electricity Generation Systems,” 2009.

[7] M. Klobasa, "Analysis of demand response and wind integration in Germany's electricity market," IET Renewable Power Generation, vol. 4, 2010, pp. 55-63.

[8] S. Stoft, Power System Economics: Designing Markets for Electricity, John Wiley \& Sons, Inc., 2002.

[9] F. Lévêque, Competitive Electricity Markets and Sustainability, London: Edward Elgar Publishers, 2006.

[10] R. Green, “Electricity and Markets,” Oxford Review of Economic Policy, vol. 21, 2005, pp. 67-87.

[11] IAE/NEA, Projected costs of generating electricity, 2010.

[12] A.D. Lamont, “Assessing the long-term system value of intermittent electric generation technologies," Energy Economics, vol. 30, May. 2008, pp. 1208-1231.

[13] B. Ummels, "Wind integration: Power System Operation with Large-Scale Wind Power in Liberalised Environments," 2009.

[14] G.S. De Miera, P. Del Rio Gonzalez, and I. Vizcaino, "Analysing the impact of renewable electricity support schemes on power prices: The case of wind electricity in Spain," Energy Policy, vol. 36, Sep. 2008, pp. 3345-3359.

[15] R. Turvey and D. Anderson, Electricity Economics: Essays and Case Studies, The Johns Hopkins University Press, Baltimore, 1977.

[16] D.T. Hoog and B.F. Hobbs, "An Integrated Resource Planning model considering customer value, emissions, and regional economic impacts," Energy, vol. 18, Nov. 1993, pp. 1153-1160.

[17] B.F. Hobbs, "Optimization methods for electric utility resource planning," European Journal of Operational Research, vol. 83, May. 1995, pp. 1-20.

[18] B.F. Hobbs, M.H. Rothkopf, R.P. O'Neill, and H.-po Chao, The next generation of electric power unit commitment models, KLUWER ACADEMIC PUBLISHERS, 2001. 
[19] E. Delarue and W. D'haeseleer, “Adaptive mixed-integer programming unit commitment strategy for determining the value of forecasting," Applied Energy, vol. 85, Apr. 2008, pp. 171-181.

[20] L. Kuntz and F. Müsgens, "Modelling start-up costs of multiple technologies in electricity markets," Mathematical Methods of Operations Research, vol. 66, Feb. 2007, pp. 21-32.

[21] EWEA, Large scale integration of wind energy in the European Power supply: analysis, issues and recommendations, 2005.

[22] H. Lund, "Management of surplus electricity-production from a fluctuating renewable-energy source," Applied Energy, vol. 76, Nov. 2003, pp. 65-74.

[23] G. Giebel, "On the Benefits of Distributed Generation of Wind Energy in Europe," 2001.

[24] F. Sensfus, M. Ragwitz, and M. Genoese, "The merit-order effect: A detailed analysis of the price effect of renewable electricity generation on spot market prices in Germany," Energy Policy, vol. 36, Aug. 2008, pp. 30863094.

[25] M. Shahidehpour and C. Wang, "Ramp-rate limits in unit commitment and economic dispatch incorporating rotor fatigue effect," IEEE Transactions on Power Systems, vol. 9, 1994, pp. 1539-1545.

[26] J. Maddaloni, A. Rowe, and G. Van Kooten, "Wind integration into various generation mixtures," Renewable Energy, vol. 34, Mar. 2009, pp. 807-814.

[27] J. Ihle and B. Owens, Integrated Coal and Wind Power Development in the U.S. Upper Great Plains, 2004. 
Figure 1: Load duration curve and optimal number of operating hours for base $(B)$, mid $(M)$, peak $(P)$ and high peak $(h P)$ technologies

Figure 2: Load duration curve of net demand levels

Figure 3: Comparison screening curve methodology and inclusion of operational constraints: Optimal $\operatorname{mix}$

Figure 4: Comparison screening curve methodology and inclusion of operational constraints:

Generation output

Figure 5: Optimal technology mix with different base load ramp rates

Figure 6: Optimal technology mix with different mid load ramp rates

Figure 7: Optimal technology mix with different levels of transmission interconnection: Base load ramp $=16.6 \%$

Figure 8: Optimal technology mix with different levels of transmission interconnection: Base load ramp $=33.3 \%$

Figure 9: Optimal technology mix with different levels of pump/turbine capacity: Base load ramp = $16.6 \%$

Figure 10: Optimal technology mix with different levels of pump/turbine capacity: Base load ramp = $33.3 \%$ 


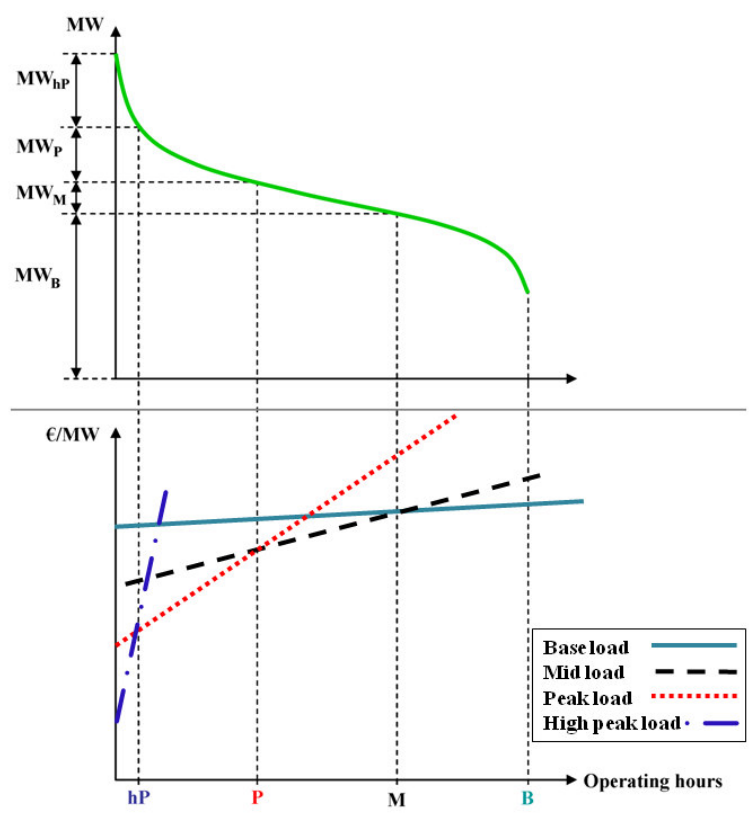




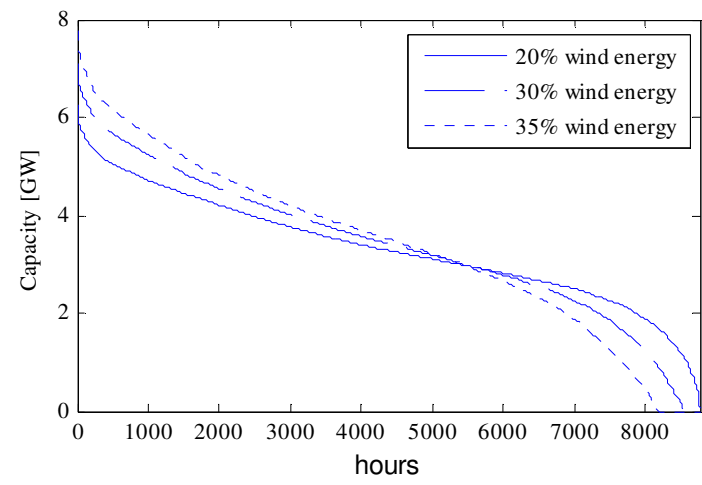




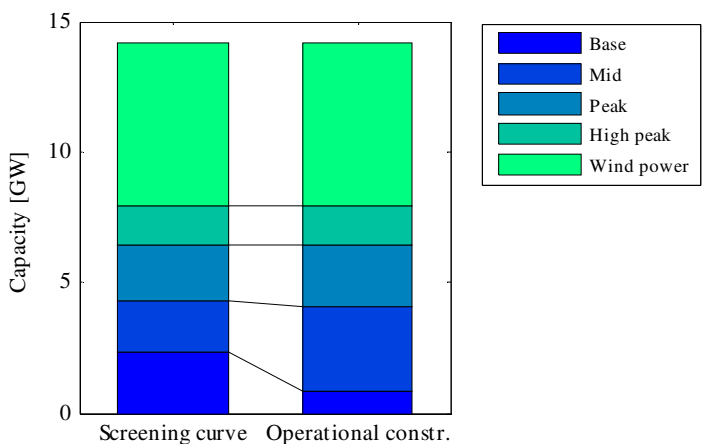



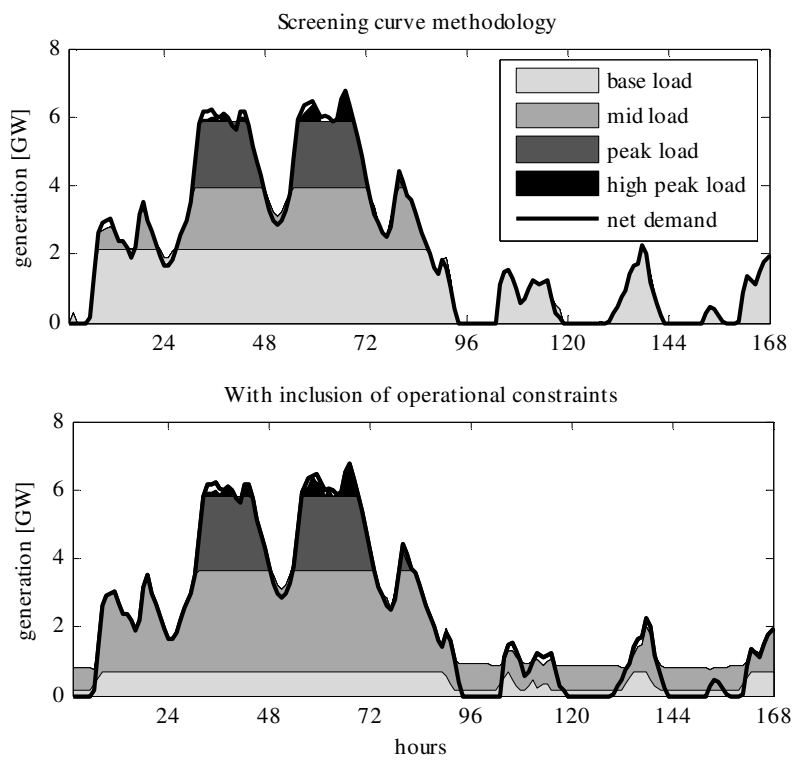


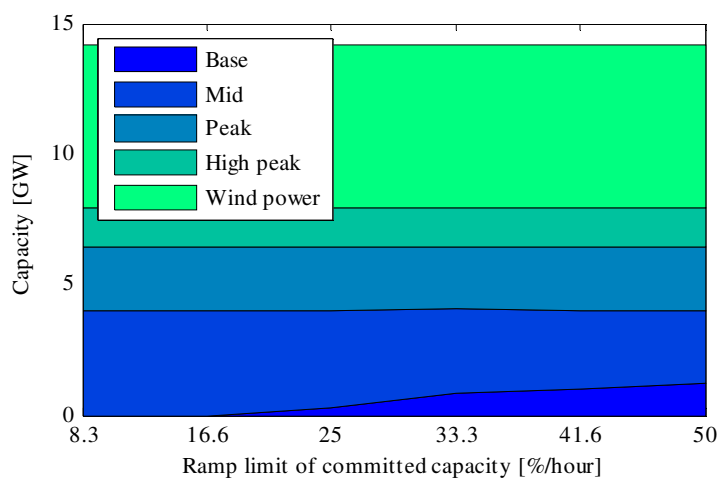




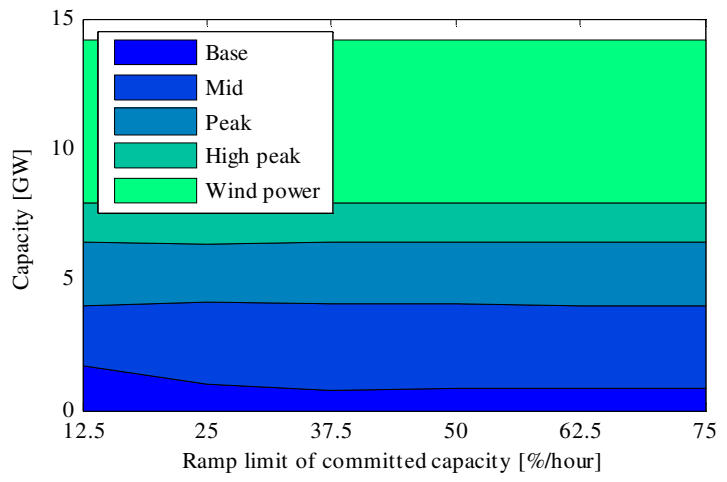




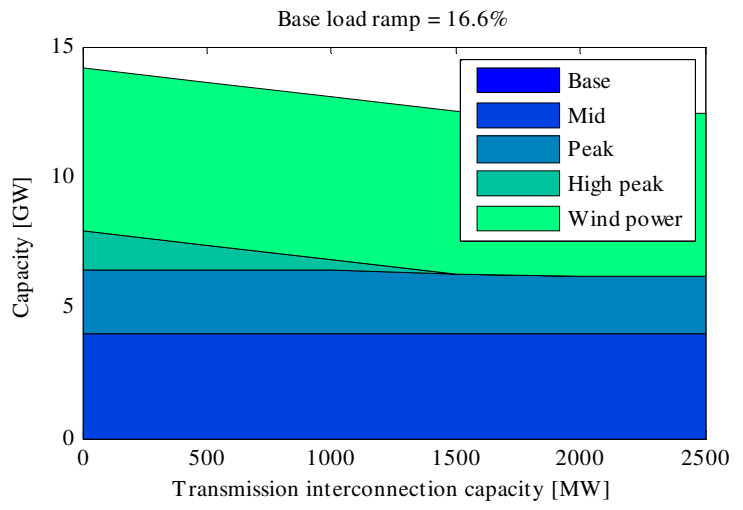




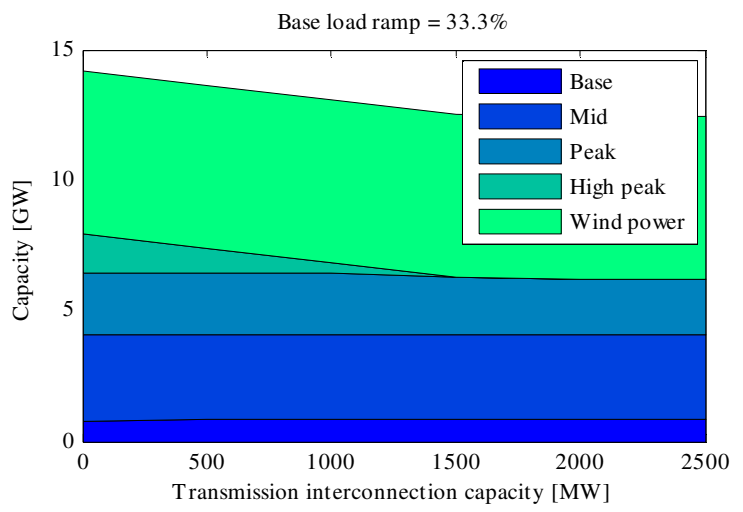




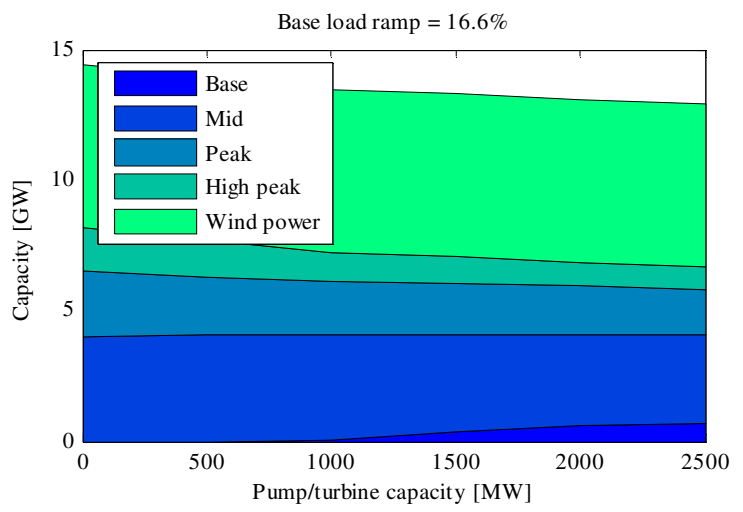




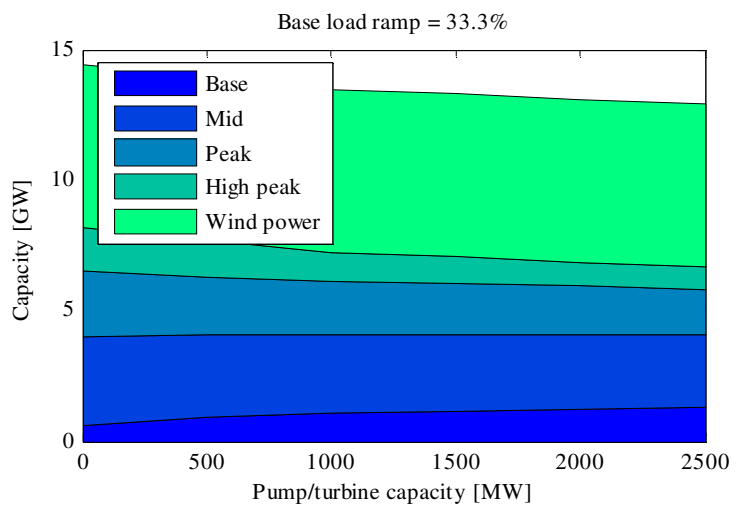

